\title{
Poder de reactivación y poder de différance: sobre la importancia de Husserl en la obra temprana de Derrida
}

\section{Power of reactivation and power of différance: on Husserl's importance for Derrida's early works}

DOI: $10.12957 /$ ek.2021.51928

\author{
Pedro Natán Tenner ${ }^{1}$ \\ Universidad Nacional de San Martín (UNSAM) \\ pedro_tenner@hotmail.com
}

\section{RESUMEN}

En el presente trabajo nos preocupamos por mostrar cómo la constitución histórica del sentido, que Husserl describe en su Origen de la geometría, muestra en modo incipiente lo que Derrida posteriormente denominará différance. Mostraremos cómo esta historicidad dependerá, para Husserl, de un poder de reactivación del sentido a partir de las sedimentaciones, y propondremos que este poder tiene un correlato en la noción derrideana de poder de différance, según aparece en De la gramatología. Pretendemos así establecer líneas de investigación sobre la influencia de Husserl en Derrida, principalmente en la obra temprana, pero con una proyección hacia la obra toda del francés.

Palabras clave: Derrida. Husserl. Deconstrucción. Fenomenología. Poder. Différance.

\section{ABSTRACT}

In this paper we will attempt to show how the historical constitution of sense, as described by Husserl in his Origin of Geometry, displays already the characteristics of what Derrida will later name différance. We will show how this historicity depends, in Husserl, of a power of reactivation of sense from sedimentations, and we will contend that this power

\footnotetext{
${ }^{1}$ Doutorando em Filosofia pela Universidade Nacional de San Martín (Argentina). Bolsista do CONICET.
} 
| Artigos | Poder de reactivación y poder de différance: sobre la importancia de Husserl en la obra temprana de Derrida | Pedro Natán Tenner |

possesses a correlative in Derrida's notion of a power of différance, as it appears in $O f$ Grammatology. We will thus attempt to establish paths of research on Husserl's influence on Derrida, initially in the latter's early texts, but with a projection towards the whole of the French philosopher's work.

Keywords: Derrida. Husserl. Deconstruction. Phenomenology. Power. Différance.

\section{Introducción}

En su ensayo "Freud y la escena de la escritura", Derrida ha observado que "los conceptos de différance y de retardo originarios se nos impusieron a partir de una lectura de Husserl" (1989: 280, n. 2). Derrida remite a continuación a su Introducción al Origen de la geometría. Siguiendo esta indicación del autor francés, es nuestro propósito, en primer lugar, investigar la manera en que la noción de différance ya está operando en El origen de la geometría y en la Introducción que Derrida escribió a ese texto, aun cuando el significante no aparezca explícitamente en ningún momento. Puntualmente, estudiaremos cómo la constitución histórica del sentido que Husserl plantea ya muestra las características de lo que Derrida posteriormente denominará différance. En segundo lugar, exploraremos la noción husserliana de un poder de reactivación constitutivo de la historicidad del sentido, y cómo ese poder, que para Husserl es finito, pero infinitizable, se vincula a un poder que Derrida ha denominado poder de différance, cuya operación depende de su esencial finitud. Observaremos cómo esta tensión entre infinitud y finitud, o potencia e impotencia, es crucial para comprender la crítica derrideana a la fenomenología, crítica ésta que resaltaremos tanto en su Introducción al texto de Husserl, como en textos posteriores; sin embargo, también daremos indicios de cómo esa tensión que mencionamos marca el punto en que el discurso husserliano influye la filosofía del autor francés, bastante más allá de sus primeros pasos.

Creemos que, dada la importancia que la différance tiene en la filosofia derrideana toda, y la marcada continuidad que los textos posteriores del autor muestran con respecto a los iniciales, puede resultar sumamente provechosa una investigación de la génesis de esta 
| Artigos | Poder de reactivación y poder de différance: sobre la importancia de Husserl en la obra temprana de Derrida | Pedro Natán Tenner |

noción. Este artículo pretende, en definitiva, marcar apenas los lineamientos de esa investigación. $^{2}$

\section{El poder de reactivación y el suplemento}

Como ya mencionamos, la importancia de Husserl para la constitución del concepto de différance la declara explícitamente Derrida en "Freud y la escena de la escritura". En "Fuerza y significación", Derrida explicita un poco más. Según señala, lo que "nos enseña a pensar Husserl en el Origen de la geometría" es que "el sentido debe esperar a ser dicho o escrito para habitarse él mismo y llegar a ser lo que es al diferir de sí” (Derrida, 1989: 21). El devenir otro de sí, o diferirse, no es algo que le advenga al sentido, como un accidente histórico, sino que es constitutivo de él. Y es así precisamente porque, para Husserl (2000: 380), la historia misma no es accidental al sentido: "la historia no es de antemano nada más que el movimiento vivo de la solidaridad y de la implicación mutua (des Miteinander und Ineinander) de la formación del sentido (Sinnbildung) y de la sedimentación del sentido originarias". ${ }^{3}$ Husserl sostiene que el sentido sólo puede constituirse a través de un constante diferirse o postergarse a sí mismo, deviniendo otro de sí en la tradición y la transmisión de época en época, según su devenir interno y propio. La interrupción de ese movimiento no es la captación definitiva y absoluta del sentido, sino el fin del sentido mismo. $^{4}$

\footnotetext{
${ }^{2}$ Con respecto a la continuidad y consistencia de la filosofía de Derrida, cf. Lawlor (2002: 211), para quien "los conceptos forjados durante el primer período (de 1954 a 1967) se mantienen en los escritos posteriores. De hecho, el rasgo más notable del pensamiento de Derrida es su continuidad". Otros autores que enfatizan esta continuidad son Ferraris (2006) y Moati (2015). Para la posición contraria, donde se enfatizan los elementos de discontinuidad entre los primeros textos derrideanos y su obra posterior, cf. Sorin (2018).

${ }^{3} \mathrm{Al}$ citar El origen de la geometría de Husserl, nos remitiremos a la traducción al español realizada por Vera Waksman a partir de la traducción al francés de Derrida. Los términos en alemán en esta y otras citas son aquellos que el propio Derrida optó por dejar en su lengua original al traducir el texto. La paginación que seguimos es la del texto original, ofrecida en los márgenes tanto en la traducción de Derrida como en la de Waksman.

${ }^{4}$ En La voz y el fenómeno, Derrida considera el marco más amplio de este movimiento de constitución del sentido histórico: el proceso husserliano de temporalización, a saber, "el proceso por el cual el ahora viviente, al producirse por generación espontánea, debe, para ser un ahora, retenerse en otro ahora, afectarse él mismo, sin recurso empírico, de una nueva actualidad originaria en la que llegará a ser no-ahora como ahora pasado, etc." (Derrida, 1985: 143). En este proceso, en que siempre faltará un ahora para clausurar la serie, "lo mismo no es lo mismo más que afectándose de lo otro, llegando a ser lo otro de lo mismo" (Derrida, 1985: 143).
} 
| Artigos | Poder de reactivación y poder de différance: sobre la importancia de Husserl en la obra temprana de Derrida | Pedro Natán Tenner |

Ahora bien, a la vez que constituye todo ente y el sentido de todo ente, la historia, para Husserl, implica un riesgo. La pérdida de sí necesaria, que el sentido opera en lo que Derrida llamará différance, introduce el peligro del olvido y la imposibilidad de recuperación. Acontecería entonces el fenómeno que Husserl denominará "crisis" de las ciencias. Por ello, para garantizar la transmisión del sentido y de la verdad "una continuidad de persona a persona, de época a época, debe haber sido practicable" (Husserl, 2000: 375). Y, más relevante para nuestro propósito, "es claro que, luego, el poder de trasladar esas proposiciones desde su vaga comprensión lingüística a la claridad de la reactivación de su sentido evidente, ese poder ha debido ser transmitido y ha de ser constantemente transmisible en su modo propio" (Husserl, 2000: $375-6){ }^{5}$

De este modo, Husserl entiende la vitalidad de una ciencia como vinculada a una diferencia en la intensidad de una fuerza, puntualmente la del poder de restaurar, en cada momento de su devenir histórico, el sentido que ha quedado oculto por las sedimentaciones de las épocas anteriores. La necesidad de recurrir a la huella de la escritura para constituir la objetividad, es decir, de recurrir a lo que Derrida denominará posteriormente una "suplementaridad originaria", ${ }^{6}$ introduce el peligro del olvido del origen. Se trata aquí, entonces, de una captación y una comprensión, algo angustiosa, de lo que, según Derrida (2000: 105), es "la grave cuestión de la finitud del poder". Pues en efecto, ante el número prodigioso de sedimentaciones de una ciencia como la geometría, "finalmente ese poder ha debido agotarse en el esfuerzo por poner en evidencia y fracasar para una productividad superior" (Husserl, 2000: 374).

Debemos remarcar que, sin embargo, la debilidad o flacidez de ese poder no conduce a algo así como la interrupción del devenir histórico de la ciencia (del movimiento de su différance, en términos de Derrida), ni a una muerte de la ciencia que fuera su

\footnotetext{
5 Debemos aclarar que aquí nos desviamos de la traducción de Waksman, quien traduce pouvoir por "capacidad". De por sí, la traducción de Derrida es peculiar, pues el término alemán que Husserl utiliza, Vermögen, se ha pensado tradicionalmente como más cercano al francés faculté o el español "facultad". Nosotros hemos optado por traducirlo por "poder", pues, como veremos más adelante, creemos que Derrida, habiendo podido optar por faculté, escoge pouvoir de manera provocativa, para inscribir el problema en el registro de la potencia, la impotencia y la finitud.

${ }^{6}$ Cf. Derrida (1985), sobre todo p. 149 y ss. Creemos que si es legítimo implementar la noción de différance como clave interpretativa de la Introducción al Origen de la geometría (algo que, como vimos, el propio Derrida nos autoriza a hacer), entonces es legítimo también aplicar la noción de suplemento, pues, como veremos, ambas nociones son inseparables.
} 
| Artigos | Poder de reactivación y poder de différance: sobre la importancia de Husserl en la obra temprana de Derrida | Pedro Natán Tenner |

desaparición, sino a otra clase de muerte de la actividad científica: la muerte que toma la forma de una actividad puramente pasiva. Así, Husserl (2000: 372) señala que siempre persiste el peligro de "un modo de la actividad, de un pensar que se mueve en pasividades puras, recogidas de manera receptiva y que sólo opera con significaciones pasivamente comprendidas y asumidas, sin esta evidencia de actividad originaria". ${ }^{7}$ Esta muerte se produce cuando se actualiza un peligro potencial, intrínseco a cualquier introducción del suplemento: el peligro de que el suplemento termine por suplantar aquello que ha hecho posible en primer lugar. ${ }^{8}$ Así, Husserl (2000: 376) describirá la ciencia moderna como una ciencia suplementaria: "la ilustración sensible de los conceptos por las figuras dibujadas sustituye el producir efectivo de las protoidealidades". ${ }^{9}$ Este carácter suplementario, como mencionamos, no hace imposible la ciencia; por el contrario, a través del "libre juego de las formaciones (Bildungen) asociativas" (Husserl, 2000: 372), "las ciencias pueden desarrollarse de manera viva a través de los siglos, sin ser por ello menos inauténticas" (Husserl, 2000: 376). Desde esa inautenticidad, esta vida será una vida suplementaria, sujeta a un devenir espectral que se moverá de asociación en asociación siguiendo una fatalidad irreflexiva, inerte y maquinal. Como señala Derrida al analizar este pasaje, "los

\footnotetext{
${ }^{7}$ Es interesante resaltar que, para Husserl, la pasividad no le adviene a la ciencia desde fuera, sino que está siempre ya introducida como riesgo, pues es el resultado de las sedimentaciones de la escritura que suplementan a la ciencia y sin las cuales ella no podría constituirse. Algo similar observa Husserl al hablar del paso de la actividad a la pasividad en el caso de la "vida intuitiva": "la vida originariamente intuitiva que, en diversas actividades, crea sobre la base de la experiencia sensible sus formaciones originariamente evidentes, muy pronto cae en medida creciente en la seducción del lenguaje. Cae por extensiones cada vez mayores en un decir y en un leer puramente sujetos a las asociaciones, tras las cuales se encuentra a menudo decepcionada por la experiencia posterior, en sus acepciones adquiridas de esta manera" (Husserl, 2000: 372). En tanto esa "caída en el lenguaje" es originaria y constitutiva en la ciencia, ésta siempre será decadente. Para que su actividad devenga en pasividad no hace falta que pase nada, o mejor, hace falta que no pase nada. No es el resultado de un acontecimiento rupturista. Es por ello que, para la ciencia, la pasividad es un peligro constante y por lo que, ante la disminución o finitud del poder de reactivación, el devenir natural será hacia esa pasividad. Parecería que todo lo que el poder puede hacer es postergar o diferir esa muerte-viva que es la actividad pasiva y que consiste precisamente en que lo que debería tener un accionar meramente suplementario (la escritura) termina por suplantar aquello a lo que suplementa. En un momento veremos esta suplantación en más detalle.

${ }^{8}$ Es de suponer que Husserl opera aquí con la noción del signo que Derrida denomina "clásica". Según esta posición la substitución que el signo opera es "secundaria y provisional": "segunda desde una presencia original y perdida de la que el signo vendría a derivar; provisional con respecto a esta presencia final y ausente en vista de la cual el signo sería un movimiento de mediación" (Derrida, 1994: 45). El momento de la crisis sería entonces el punto en que no se concreta el rodeo que el signo constituye, y la cosa presente no se recupera. Por supuesto, Derrida busca contraponer una noción del signo donde la presencia de la cosa siempre está ya perdida y es eminentemente irrecuperable.

${ }^{9}$ Las itálicas son nuestras.
} 
| Artigos | Poder de reactivación y poder de différance: sobre la importancia de Husserl en la obra temprana de Derrida | Pedro Natán Tenner |

progresos de la ciencia pueden proseguirse aun cuando se ha perdido el sentido de origen. Pero la logicidad misma de los gestos científicos, cautivos de la mediatez, se atasca entonces en una especie de absurdo onírico e inhumano” (Derrida, 2000: 108).

\section{El carácter constitutivo de la crisis}

Reiteremos: la pasividad es el resultado de una diferencia en la intensidad de la fuerza, de un devenir impotente del poder o, en otras palabras, de la falta de "justamente lo que había dado, o mejor, ha debido dar a todas las proposiciones y teorías un sentido archioriginario que siempre se debe poner nuevamente en evidencia" (Husserl, 2000: 377). ${ }^{10} \mathrm{Si}$, para nombrar el devenir histórico de la ciencia que Husserl describe, adoptamos la noción derrideana de différance (algo que, como vimos, el propio Derrida nos autoriza a hacer), parecería que hubiera que postular algo así como dos modos de ella: 1) una différance auténtica y propia, producto de un poder de reactivación potente y capaz de transmitir históricamente el sentido originario, en un devenir y una historia internas a ese mismo sentido (y que lo constituye), y 2) una différance suplementaria y espectral que toma el lugar de la primera y es de hecho su muerte, resultado de una falta en el poder y que planteará una historia desviada, vacía de sentido y exterior a él. ${ }^{11}$

Ahora bien, para Derrida, esta consciencia de una finitud del poder debería llevar a Husserl a replantearse el sentido mismo de la historicidad de la ciencia que el Origen de la geometría busca explicitar. Así, Derrida (2000: 106) se pregunta: “¿no es necesario también que el olvido "crítico" de los orígenes no sea el extravío accidental, sino la sombra fiel al

\footnotetext{
${ }^{10}$ Resultan de interés los dos sentidos en que Husserl utiliza el concepto de "deber". Por un lado, se trata de lo que debía ocurrir y, podemos deducir, lo que no debía ocurrir: el poder debía garantizar la preservación del sentido, es decir, no debía flaquear. Por otro lado, se trata de lo que debió ocurrir, en tanto catástrofe inevitable: necesariamente, el poder terminó por flaquear. Derrida recoge este mismo doble sentido en su texto Scribble poder/escribir. Allí, el autor francés enfatiza el movimiento resumido en la sentencia de que "lo que no debía ocurrir debió ocurrir" (Derrida, 1979: 131). Derrida considera que la articulación de los dos sentidos del deber invita a pensar la transgresión y el desvío como la norma. El acontecimiento de desvío no es algo que advenga contingentemente, sino que es constitutivo, pero sin perder jamás su sentido de desvío.

${ }^{11}$ Por supuesto, nuestro punto será resaltar que la différance es un movimiento siempre ya de impropiedad, y que por lo tanto esta dicotomía es ficticia. Volveremos sobre este punto más adelante, cuando tratemos lo que Derrida denomina "poder de différance" y el efecto que tendría la infinitización de ese poder. Como veremos, deberán contraponerse las características de una différance plena e infinita (que sería imposible y no podría devenir nunca en nada) y una siempre ya suplementaria.
} 
| Artigos | Poder de reactivación y poder de différance: sobre la importancia de Husserl en la obra temprana de Derrida | Pedro Natán Tenner |

movimiento de la verdad?" El olvido de los orígenes y la crisis no serían entonces advenedizos a la ciencia, sino la forma misma de ella. En efecto, es posible rastrear en el texto de Husserl las huellas de una impotencia que no adviene al poder, sino que lo constituye e inicia también toda posibilidad de una historia y un desarrollo científicos. Se trata de la impotencia que condujo en primer lugar a recurrir al signo y al devenir lenguaje de la ciencia. Husserl (2000: 370-1) observa que un único sujeto individual no puede completar la constitución de la objetividad y que surge "de manera inteligible, en cuanto tomamos en consideración la función de la intropatía y la cohumanidad como comunidad de intropatía y co-munidad de lenguaje". Una falta intrínseca produce que el sentido no pueda existir hasta que haya sido suplantado por su signo: debe aparecer en su desaparecer. ${ }^{12}$ Pero a su vez, el suplemento del habla no basta, y deberá ser suplementado por la escritura. Hasta entonces, a la objetividad "le falta la presencia perdurante de los 'objetos ideales' [...] Le falta el ser-a-perpetuidad, que permanece aun cuando nadie lo ha efectuado en la evidencia" (Husserl, 2000: 371). ${ }^{13}$

No sólo el signo no se introduce como algo accidental o advenedizo (como ya resaltamos más arriba), sino que lo hace para compensar una falta del poder. Es porque el poder ya ha siempre faltado que siquiera se recurre al signo. Pero, como vimos antes, el paso de una suplementación meramente accesoria, o de un suplemento "domesticado" y obediente, a la total suplantación depende precisamente de una falta en el poder. Así, si el poder siempre faltó, el suplemento siempre suplantó. Como el sentido no pudo presentarse a sí mismo, debió ser dicho y luego escrito, es decir, debió quedar reemplazado por su imagen espectral. Pero este reemplazo no es una posibilidad entre varias. No es posible una différance, un devenir otro en el signo o un diferir de sí, que a su vez permita un desarrollo

\footnotetext{
${ }^{12}$ Es interesante resaltar, sin embargo, que para Husserl esta suplantación no implica todavía riesgo, pues el signo lingüístico oral persiste en la transparencia: "Las producciones pueden propagarse en su similaridad de personas a comunidades de personas y, en el encadenamiento de comprensión de esas repeticiones, penetra la evidencia como lo mismo en la conciencia del otro. En la unidad de la comunidad comunicante de varias personas, no se tiene conciencia de la formación producida de manera iterativa como de una formación semejante, sino como de la única formación universal" (Husserl, 2000: 371). Pero como vimos, y como reiteraremos en un momento, esa persistencia unívoca en "lo mismo" va en contra del sentido propio de la historia y la différance, donde el devenir otro no es sólo inevitable, sino también constitutivo. La transmisión oral ya ha olvidado el sentido originario tanto como la escritura, algo que llevará a Derrida a considerar que el habla y la anotación son en realidad dos formas suplementarias de la archi-escritura y la différance (cf. $L a v o z$ y el fenómeno y De la gramatología).

${ }^{13}$ Las itálicas son nuestras.
} 
| Artigos | Poder de reactivación y poder de différance: sobre la importancia de Husserl en la obra temprana de Derrida | Pedro Natán Tenner |

interno, potente o bajo el control estricto del poder. Si la différance comenzó (y necesariamente siempre ya comenzó) es porque el poder ha faltado. La posibilidad que mencionamos de una différance "auténtica" que constituyera una historia propia y plenamente interna nunca está dada. Por ende, la crisis será la única forma fáctica de la ciencia, no un desvío a partir de un estado de normalidad, pues el sentido sólo puede operar desde el olvido y la suplantación. Derrida (2000: 106) resume esta idea señalando que "una reactivación total, aun cuando fuera posible, paralizaría la historia interna de la geometría, tanto como lo haría la imposibilidad radical de toda reactivación". Si fuera plenamente interna y potente, la historia de la ciencia sería idéntica al fin de toda historia. ${ }^{14}$

\section{La Idea y la infinitización del poder}

Sin embargo, Husserl se anticipa a esta objeción que, guiados por Derrida, podemos extenderle. En efecto, el autor alemán considera posible una "infinitización de nuestro poder" por medio del salto a la Idea o la "idealización: a saber, la liberación fuera de sus límites" (Husserl, 2000: 375). Sin embargo, es posible demostrar que semejante infinitización no responde nunca a un infinito actual y plenamente desplegado, sino a un infinito potencial, constituido por la finitud (y por ende acechado por ella).

En primer lugar, debemos aclarar que, para Husserl, la Idea no es, como explicitará en Ideas I, equivalente a un eidos esencial platónico, sino que adopta el sentido kantiano de polo regulativo, y de apertura indefinida e indeterminada hacia una potencial infinitud. ${ }^{15}$ Por ello, la Idea sólo puede constituirse en un devenir histórico. Así, al tratar el tema de la Idea husserliana, Derrida (2000: 149) señalará que

\footnotetext{
${ }^{14} \mathrm{Al}$ hablar del poder y la fuerza, Derrida resalta siempre el hecho de que la diferencia no les es extrínseca, y por lo tanto no lo es tampoco el límite, la finitud ni la muerte. La fuerza siempre es la diferencia entre las fuerzas, y el poder es la diferencia entre los poderes. Ningún poder puede plenamente pues depende, para constituirse en poder, de quedar limitado por otros poderes. Por ello es esencialmente finito. Cf. Derrida (1994: 52). Como desarrollaremos en un breve excurso (cf. n. 21 de este artículo), creemos que aquí opera una cuasi-identificación entre fuerza, poder y voluntad, según ha visto Heidegger en su lectura de Nietzsche: " "fuerza' es entendida por Nietzsche siempre en el sentido de poder, es decir, como voluntad de poder" (Heidegger, 2000: 218).

${ }^{15}$ Cf. Husserl (1962: 12).
} 
| Artigos | Poder de reactivación y poder de différance: sobre la importancia de Husserl en la obra temprana de Derrida | Pedro Natán Tenner |

Sin duda, la Idea y la Razón oculta en la historia y en el hombre como "animal rationale" son eternas. Husserl lo afirma a menudo. Pero esta eternidad no es sino una historicidad. Es la posibilidad de la historia misma. Su supratemporalidad - respecto de la temporalidad empírica- no es sino una omnitemporalidad. La Idea, como la Razón, no es nada fuera de la historia donde ella se expone, esto es, donde en un único y mismo movimiento, se despliega y se deja amenazar.

Pero a la inversa, es sólo la infinitización lo que hace posible una historia. Así, según Derrida, Husserl considerará que sólo la historia europea (devenida infinita y opuesta a las historias empíricas de los pueblos no europeos) puede llamarse legítimamente "historia":

La apertura del infinito, lejos de ser el acceso a algún posible, ahistórico en sí y descubierto en una historia que resultaría por eso transfigurada, no es, por el contrario, sino la apertura de la historia misma, en la mayor profundidad y en la mayor pureza de su esencia. Sin este desgarramiento de lo finito, la humanidad histórica o, más bien, las humanidades históricas, no habrían tenido más que la unidad socioantropológica de un tipo empírico. Ahora bien, y lo hemos visto claramente: una historia empírica no se distingue esencialmente de una nohistoria (Derrida, 2000: 137)

Derrida rastrea este problema de una historia infinita y una historia empírica en una dicotomía equivalente, que ya mencionamos brevemente: la de una historia intrínseca y una extrínseca. Si bien Husserl reconoce que la verdad sólo puede constituirse de manera histórica y a través de la inscripción, debe hacerlo siguiendo una historia puramente interior y una escritura que, en última instancia, no se inscribe en el mundo. La idealización será entonces una "liberación absoluta" (Derrida, 2000: 93) del mundo y lo real y la historia interna/infinita no estará entonces ligada "ni a este momento ni a este territorio ni a este mundo, sino al todo-del-mundo (Weltall)" (Derrida, 2000: 94). Su archivo no constituirá un objeto en el mundo, sino que estará trazado en la forma misma de cualquier mundo: su inscripción se tallará directamente en el ser. ${ }^{16}$ No estará sujeta a ninguna clase de

\footnotetext{
${ }^{16}$ Tres décadas después, en Mal de archivo, Derrida volverá sobre este problema de un archivo del ser o de la existencia en general, independiente de toda facticidad mundana. Se preguntará así si "una existencia en general, puede recibir y registrar, archivar un acontecimiento, en la sola medida en que la estructura de esta existencia y de su temporalización haga esta archivación posible" (Derrida, 1997: 88). En términos similares a los que estamos tratando aquí, la interrogante se desplazará, en ese texto posterior, entre la necesidad de una archivabilidad originaria para pensar un archivo concreto, y a la inversa, la necesidad de un "primer archivo" fáctico y suplementario desde donde pensar la archivabilidad en general.
} 
| Artigos | Poder de reactivación y poder de différance: sobre la importancia de Husserl en la obra temprana de Derrida | Pedro Natán Tenner |

exterioridad, y será por ende inalcanzable por cualquier destrucción fáctica del mundo. ${ }^{17} \mathrm{De}$ hecho, como vimos, para Husserl uno de los aspectos constitutivos de la escritura es su permanencia. Una historia infinita sólo podría, aparentemente, ser constituida por una escritura indestructible e infinita.

La posibilidad de infinitizar el poder de reactivación en el salto a la Idea depende precisamente de encontrar esa escritura infinita y ese archivo del ser. Es decir, de encontrar un signo puramente interior, que suplemente pero no suplante a aquello que ha suplementado. Esto es así porque la Idea no es algo, no es algo que es, y por lo tanto no puede devenir fenómeno en el mundo. Ni siquiera en algo así como un mundo eidético platónico, como ya mencionamos. Por el contrario, Derrida (2000: 152) dirá que la Idea husserliana

es aun menos un ser que el eidos, si ello es posible; porque el eidos es un objeto determinable y accesible a una intuición finita. La Idea no lo es. Ella está siempre epékeina têhs ousías. Télos de la determinabilidad infinita del ser, no es sino la apertura del ser a la luz de su fenomenalidad, luz de la luz, sol del sol visible, sol oculto que muestra sin mostrarse. ${ }^{18}$

Ahora bien, en su Introducción al texto de Husserl, Derrida desliza una crítica a la noción de una escritura y una historia puramente interiores e infinitas: "la historicidad o el ser en historia es, precisamente, la posibilidad de estar intrínsecamente expuesto a lo extrínseco" (Derrida, 2000: 94). Es esta crítica, y su particular articulación de lo interior y lo exterior, la que el autor francés retomará posteriormente, sobre todo en La voz y el fenómeno, De la gramatología y La escritura y la diferencia. Así, en "Fuerza y significación", Derrida (1989: 16) hablará de una escritura que constituyera "una salida fuera del mundo, hacia un lugar que no es ni un no-lugar, ni otro mundo, ni una utopía ni una coartada". Esta escritura se grabaría sobre "el exceso sobre el todo, esa nada esencial a partir de la cual puede aparecer todo y producirse en el lenguaje" (Derrida, 1989: 16).

Derrida considera este deseo de infinitización necesario para cualquier proyecto de constitución de sentido y, al mismo tiempo, completamente inalcanzable. En efecto, la

\footnotetext{
${ }^{17}$ Cf. Bower (2015). Allí, el autor se ha preocupado por el problema de un pre-mundo como posible región de inscripción de las reglas de constitución de toda subjetividad mundana, y su supervivencia a la destrucción fáctica del mundo que Husserl contempla en Ideas I.

${ }^{18}$ Sobre la idea como polo de los infinitos "apareceres" de las determinaciones de la cosa, polo éste que sin embargo (y necesariamente) no aparece, cf. Ideas I, sobre todo §143 y pp. 357-8.
} 
| Artigos | Poder de reactivación y poder de différance: sobre la importancia de Husserl en la obra temprana de Derrida | Pedro Natán Tenner |

escritura "crea el sentido consignándolo [...] a una superficie que se pretende que sea transmisible hasta el infinito" (Derrida, 1989: 23). La historicidad pura, que constituye una "ruptura con el medio de la historia empírica", es también el telos de una "historia de la escritura, cuya filosofía permanecerá siempre en el futuro" (Derrida, 1989: 23). Derrida reconoce entonces una voluntad de escribir que se constituye en un querer inscribirse en la pura interioridad de la historia ideal. ${ }^{19}$ Sin embargo, la escritura no podrá nunca prescindir de la arbitrariedad transgresora con respecto a esa pura interioridad. Estará siempre precipitada hacia el exterior: "no sabe adónde va, ninguna sabiduría la resguarda de esta precipitación esencial hacia el sentido que ella constituye" (Derrida, 1989: 21). De la misma manera, el carácter de pura permanencia que Husserl creía ver en la huella escritural no aparece realmente en ella: así, Derrida (1989: 315) observa que la huella

está constituida por la amenaza o la angustia de su desaparición irremediable, de la desaparición de su desaparición. Una huella indeleble no es una huella, es una presencia plena, una sustancia inmóvil e incorruptible, un hijo de Dios, un signo de la parousía y no una semilla, es decir, un germen mortal.

Así, en tanto que no puede reducir la exterioridad de la escritura, el proyecto de una historia pura, interior e infinita estará siempre amenazado por la finitud. Como señala Derrida (1989: 23), "que se cumpla o no ese proyecto de tradición infinita, de todas formas hay que reconocerlo y respetarlo en su sentido de proyecto. El que siempre pueda fracasar es la señal de su pura finitud y de su pura historicidad". La historicidad pura sólo puede existir desde una pura finitud, es decir, fuera de sí, en una impureza empírica que acecha la

\footnotetext{
${ }^{19}$ Como sabemos, una de las tesis principales de la filosofía derrideana es que la escritura no comenzó en un momento histórico particular, ni advino nunca a un habla pura. También el habla es una forma de escritura mundana, por lo que también estará imposibilitada de la idealidad pura (cf. sobre todo La voz y el fenómeno y De la gramatología). De hecho, en De la gramatología Derrida sostiene que la escritura existe hasta en las formas más elementales de vida. Por ello, la interpretación teleológica de la historia de la escritura podría extenderse en general a la historia de la vida toda. La vida toda sería un intento de alcanzar una escritura pura, desprovista de toda realidad y exterioridad mundanas, y trazada en el ser mismo. La escritura fonética humana, y su subyectil virtual contemporáneo, serían la culminación apenas provisoria de una historia que tendría sus orígenes en los orígenes de la vida misma (es decir, que no tendría origen). De hecho, creemos que detrás de la concepción teleológica de la escritura se esconde una concepción de la animalidad toda, a saber, la animalidad como el camino desde una pura interioridad que debió ser, pero no pudo ser, hacia la reconstrucción de esa interioridad, bajo una forma suplementaria y protética, en la técnica contemporánea, sobre todo en los archivos virtuales, que simulan una existencia no mundana.
} 
| Artigos | Poder de reactivación y poder de différance: sobre la importancia de Husserl en la obra temprana de Derrida | Pedro Natán Tenner |

idealidad. ${ }^{20}$ El infinito es finito, puede morir. Pero a la inversa, la historia finita sólo puede tener el sentido del suplemento de una historia infinita que estará siempre diferida. Finitud e infinitud se implican mutuamente. ${ }^{21}$

\section{La finitud del poder de différance y la vida transcendental}

Como vemos, Derrida sigue a Husserl y al mismo tiempo se aleja de él. Si bien concordará en la necesidad de la historia infinita como proyecto, la imposibilidad de una escisión quirúrgica entre la idealidad y el mundo empírico (pues la idealidad sólo puede preservar su sentido de idealidad inhiriendo en el mundo) lo harán consciente de la necesidad de una finitud irreductible e insuperable. La libertad absoluta de la idealidad está siempre por venir. Ahora bien, mientras que, como vimos, Husserl considera que el salto a la idealidad es la infinitización del poder, Derrida postulará un poder necesaria y esencialmente finito, siempre acechado por su propia impotencia. Se tratará del poder de différance.

Este poder lo menciona Derrida en De la gramatología, donde lo relaciona no a la historicidad interna a la ciencia, sino a la historicidad de la vida en general. Derrida considera que este poder está vinculado a la creación de una reserva. Así, señala que el poder de différance actúa "en el origen de la vida en general, cuando, en niveles muy

${ }^{20}$ Desde luego, ello es así desde que, como señala Derrida, la idea husserliana es una apertura, que deberá abrirse necesariamente a su exterior. La pura interioridad existe sólo como ese "volcarse" al exterior. Aunque no podemos introducirnos aquí en el tema, la indistinción entre finitud e infinitud que queremos insinuar puede ya rastrearse en el problema de la diferencia ontológica y la diferencia entre significante y significado. Cf. Baring (2011: 290), quien nos recuerda que Derrida asevera frecuentemente que "para Heidegger el sentido del ser no es nada (rien) fuera de sus manifestaciones ónticas; no hay un ser desprendido de una forma determinada particular, y por lo tanto la diferencia entre significado y significante también es nada (rien)."

${ }^{21}$ Cf. también "Cogito e historia de la locura", donde Derrida señala que "la historicidad en general sería imposible sin una historia de la filosofía y creo que ésta sería imposible a su vez si no hubiese más que hipérbole, por una parte, o si no hubiese, por otra parte, más que estructuras históricas determinadas, Weltanschauungen finitas. La historicidad propia de la filosofía tiene su lugar y se constituye en ese pasaje, en ese diálogo entre la hipérbole y la estructura finita" (Derrida, 1989: 86). Resulta interesante que, en ese artículo, Derrida retoma el concepto de reactivación: así, la hipérbole infinita "se dice, se reafirma y decae, se olvida, de forma necesaria, hasta su reactivación, su despertar en otra ocasión de decir el exceso, que más tarde será también otra decadencia y otra crisis" (Derrida, 1989: 86). En el vocabulario de ese pasaje queda claro a qué punto la comprensión derrideana de la historia está influenciada por Husserl. Tanto en este aspecto puntual, como en nuestro trabajo todo, buscamos resaltar que, de alguna manera, el escapar de la fenomenología por parte de Derrida es necesariamente un permanecer en ella, pues la fenomenología ya incluye todos sus "afueras". 
| Artigos | Poder de reactivación y poder de différance: sobre la importancia de Husserl en la obra temprana de Derrida | Pedro Natán Tenner |

heterogéneos de organización y complejidad, es posible diferir la presencia, vale decir el gasto o el consumo, y organizar la producción, vale decir la reserva en general" (Derrida, 1986: 170). Pero precisamente por esta necesidad de una reserva, el poder no podrá infinitizarse, pues esa infinitización apenas se diferenciaría del consumo de la reserva toda. Derrida (1986: 170) dirá entonces que

Es justamente lo propio del poder de différance modificar cada vez menos la vida a medida que se extiende. Si se volviera infinito -lo que su esencia excluye $a$ priori - la vida misma sería restituida a una impasible, intangible y eterna presencia: la différance infinita, Dios o la muerte.

Así, este poder deberá estar siempre afectado por su finitud. ${ }^{22}$ Ahora bien, vemos que Derrida vincula este poder a la constitución de la vida, pues, como ha observado

${ }^{22}$ Quisiéramos, en este punto, introducir un breve excurso para profundizar en este poder finito que Derrida describe. Es nuestra opinión que la manera en que el autor francés comprende aquí el poder está influenciada por la lectura de Nietzsche que Heidegger desarrolló en las décadas de 1930 y 1940. El propio Derrida señala, en De la gramatología, que, para salvar a Nietzsche de la interpretación que lo considera el último metafísico, "tal vez no sea necesario sustraerlo de la lectura heideggeriana, sino ofrecerlo totalmente, suscribir sin reservas a esta interpretación" (Derrida, 1986: 27). En su obra Nietzsche, Heidegger describe un poder que, en tanto existe como voluntad de poder, se conserva a través de su propia sobrepotenciación ("El poder es poder sólo y mientras siga siendo acrecentamiento de poder y se ordene a sí mismo más poder") (Heidegger, 2000: 216). Conservarse y superarse son aquí la misma cosa; el poder permanece en sí, o sigue siendo sí mismo, sólo en tanto que sale de sí para volverse contra sí y superarse. Asimismo, se trata de un poder que está acechado por la finitud, o mejor dicho, que es él mismo la finitud, pues en su colocarse metas que superar no puede nunca extenderse hacia el infinito: "la esencia de la misma voluntad de poder requiere en cada caso para su conservación, y por lo tanto precisamente para la respectiva posibilidad de acrecentamiento, que esté siempre delimitada y definida en una forma fija, es decir, que sea ya en su totalidad algo que se limita a sí mismo. A la esencia del poder le es inherente estar libre de metas, y por lo tanto carecer de metas. Pero esta carencia de metas, precisamente porque requiere únicamente una posición de metas condicionada en cada caso, no puede tolerar un fluir desbordado del poder" (Heidegger, 2000: 231). Es decir que el poder no es algo que esté jamás presente o dado como un infinito actual y desbordado. El poder no puede desbordarse porque con cada superación debe asegurarse una reserva de sí: nunca está todo allí, no puede totalizarse. Es más bien un indefinido y constante diferir de sí que opera a partir de un detenerse y reactivarse en una nueva superación. La estructura de poder que describe Heidegger es sumamente similar a la de la différance derrideana y la reactivación husserliana. De hecho, entre el poder, la différance y la reactivación se da una situación similar a aquella entre el poder y la voluntad. Para Heidegger, "la voluntad no es simplemente poder y el poder no es simplemente voluntad. En lugar de ello, hay que decir lo siguiente: la esencia del poder es voluntad de poder y la esencia de la voluntad es voluntad de poder" (Heidegger, 2000: 216). En otros términos, poder y voluntad son lo mismo, pero no son idénticos entre sí. Podríamos decir, entonces, que las expresiones "poder de différance" y "poder de reactivación" operan de la misma manera que la expresión "voluntad de poder". El poder es siempre ya poder de reactivación/différance, y la reactivación/différance es siempre ya poder de reactivación/différance. No se puede pensar uno de los términos vinculados por el "de" sin desplazarse hacia el otro inmediatamente. No se puede pensar el poder sin su diferir de sí o reactivarse, ni se puede pensar ese diferir de sí o esa reactivación sin una estructura de poder. Hacerlo sería pensar un poder infinito y desbordado (algo que, como vimos, Derrida prohíbe tanto como el Nietzsche de Heidegger) o sería pensar una différance sin diferir o una reactivación sin un detenerse a partir del cual reactivarse (es decir, pensarlas como contrarias a sus esencias). Aunque no podemos desarrollar el punto aquí, creemos que esta 
| Artigos | Poder de reactivación y poder de différance: sobre la importancia de Husserl en la obra temprana de Derrida | Pedro Natán Tenner |

Francesco Vitale (2018: 27), se trata en este pasaje de una "interpretación de la différance como la condición estructural de la vida". Pero ello no debe disuadirnos de relacionar el poder de différance con el poder husserliano de reactivación o idealización. No sólo porque, inevitablemente, la ciencia ocurre en la vida y como una de sus formas, sino principalmente porque, para Derrida, la idealidad husserliana alcanza su plenitud cuando se identifica con el concepto husserliano de vida transcendental: "la forma última de la idealidad [...], la idealidad de la idealidad es el presente viviente, la presencia a sí de la vida transcendental" (Derrida, 1985: 42). La ciencia como constitución de objetidades ideales sería entonces el momento de presencia a sí de la vida, pero de una vida que está afectada por una différance pura e infinita, y que por ende es idéntica a una nada que es al mismo tiempo Dios y la muerte.

Esta misma identidad entre vida, idealidad y muerte puede deducirse a partir de otra descripción que Derrida hace de la différance, en su artículo titulado, justamente, "La différance":

Si la différance es lo que hace posible la presentación del presente, ella no se presenta nunca como tal. Nunca se hace presente. A nadie. Reservándose y no exponiéndose, excede en este punto preciso y de manera regulada el orden de la verdad $[\ldots]$ En toda exposición estaría expuesta a desaparecer como desaparición, correría el riesgo de aparecer: de desaparecer (Derrida, 1994: 41-2). ${ }^{23}$

Son claras las similitudes con la descripción, que citamos más arriba, de la Idea husserliana. En ambos casos, Derrida describe una apertura que es condición de posibilidad de la presencia del ente o de su fenomenalización, pero que ella misma no es nada, ni llega

reapropiación de la estructura de poder por parte de Derrida, para aplicarla al dislocamiento originario de la différance, es parte de esa exacerbación de la lectura heideggeriana de Nietzsche que finalmente liberaría a este último de esa misma lectura. Ese movimiento de dislocación, de diferencia y diferimiento, que Nietzsche habría descubierto en la base del ser, y que implica la muerte de la presencia en aquello mismo que constituye la presencia, coloca ya al pensador alemán del otro lado de la clausura de la metafísica, aun cuando su texto pertenezca inevitablemente a la era de la metafísica (como Heidegger insiste correctamente). Como ya mencionamos, creemos que este gesto de reapropiación deconstructiva ya hace notar su fuerza dislocadora desde el momento en que Derrida decide traducir el Vermögen husserliano por "poder" en lugar de "facultad", para inscribirlo entonces en la nueva lógica de la finitud del poder con que Nietzsche (a pesar de Heidegger) socava los presupuestos de la metafísica de la presencia.

${ }^{23}$ La cópula "es" se encuentra tachada en el original. No podemos explicar en detalle aquí por qué Derrida escoge escribirlo así; no obstante, citamos otra frase del mismo artículo donde se da un indicio: "Es la determinación del ser en presencia o en entidad [étantité] lo que es interrogado por el pensamiento de la différance". Como ya ocurría en los textos tardíos de Heidegger, la tachadura viene a cuestionar la supuesta transparencia de un ser que, como ente, viene a palabra. Para una explicación más detallada, cf. Derrida (1986: 31-32). Allí se dice que la tachadura "es la última escritura de una época". 
| Artigos | Poder de reactivación y poder de différance: sobre la importancia de Husserl en la obra temprana de Derrida | Pedro Natán Tenner |

nunca a aparecer o fenomenizarse, salvo en su desaparición. Ni la Idea, ni la différance pueden ser jamás ellas mismas, sino que (no) existen ya siempre fuera de sí, ya suplantadas. Siempre en reserva. Lo mismo puede decirse de la vida transcendental si seguimos la interpretación de Andrea Staiti (2014: 62):

Es la vida transcendental la que lleva a cabo la constitución transcendental [...] En este sentido, el "mundo de la vida" coincide con la constitución transcendental [...] La vida transcendental no es, en el fondo, nada más que este hacerse-unmundo y el mundo no es nada más que este mundo de la vida.

La vida transcendental se trata entonces de una (in)existencia "anterior" al mundo, que (no) existirá siempre ya fuera de sí, suplantada por lo viviente. ${ }^{24}$ Algo similar observa Lawlor, con respecto a una impotencia intrínseca al presente viviente husserliano (que, recordemos, para Derrida es la presencia a sí de la vida transcendental). Puntualmente, Lawlor (2002: 139) señala que la "nueva lógica" de Derrida se resume en que "la impotencia para salir del presente viviente implica que debo quedarme dentro de los límites del presente viviente. Pero, a la inversa, la impotencia para permanecer en reposo implica que debo exceder los límites del presente viviente”. Así, la única manera de permanecer dentro de los límites de la vida transcendental (algo inevitable) es siempre ya haberlos excedido (algo también inevitable). ${ }^{25}$

De esa manera, siguiendo la descripción que citamos de la différance (o de las otras dos nociones tan cercanas a ella: la Idea o la vida transcendental) podemos retomar la distinción que hicimos más arriba sobre dos modos de la différance: uno auténtico y otro suplementario. La différance auténtica se revelará entonces como aquella que es efectuada

\footnotetext{
${ }^{24}$ Sobre la relación entre la vida transcendental y el mundo de la vida, y cómo aquélla se "disuelve" (geht auf) en la constitución de un mundo de vivientes, ver el texto de Husserl "Die Vorgegebenheit der Welt und vorgegebener Weltbestände" (Hua XXXIX: 1-38), sobre todo p. 22. La interpretación de Staiti depende de una atenta y minuciosa lectura de ese texto.

${ }^{25}$ Concordamos aquí también con Bernet (1993: 156), quien, en la economía de la interpretación derrideana, ha equiparado la Idea husserliana a la "teleología de la vida transcendental". Según Bernet (1993: 156-7), la manera en que Husserl se aproxima a esta última constituye "una nueva meditación sobre un origen que es efectivo porque se lo difiere y porque invita al sujeto a someterse a una tarea infinita [...] El sujeto se encuentra dividido entre la finitud de su existencia, por un lado, y la interpelación de la idea del infinito, por el otro." Todo ello supone que Derrida "intenta forjar una nueva comprensión de la consciencia transcendental y no su destrucción" (Bernet 1993:148).
} 
| Artigos | Poder de reactivación y poder de différance: sobre la importancia de Husserl en la obra temprana de Derrida | Pedro Natán Tenner |

por un poder infinito, y que, en su actualidad infinita, no puede ser nunca nada. ${ }^{26} \mathrm{La}$ suplementaria es aquella que es efectuada por un poder siempre finito, y que está en lugar de ese infinito actual. De allí que Derrida (1985: 149) señale que "la suplementaridad es realmente la différance". Y también "la différance infinita es finita. No se la puede pensar, pues, ya, en la oposición de la finitud y de la infinitud, de la ausencia y de la presencia, de la negación y de la afirmación" (Derrida, 1985: 165). La différance infinita, la Idea o la presencia a sí de la vida transcendental sólo puede ser ella misma en tanto que se ha perdido a sí misma; podríamos decir, en tanto que se "recorre" a sí misma de finitud en finitud. Y ello sólo es posible siempre que el poder persista en su finitud. La infinitización del poder con que Husserl esperaba garantizar la idealidad de las objetidades científicas sería, en cambio, el fin de toda idealidad, pues sería el consumo de la reserva que la Idea es.

\section{Conclusión}

Lawlor (2002: 138) ha resaltado cómo, para Derrida, el discurso fenomenológico está "tensionado entre lo infinito y lo finito". Creemos que es sobre esa tensión que se basa tanto la crítica del filósofo francés a la fenomenología, como su admiración por el discurso husserliano. Para Derrida, la fenomenología está escindida internamente entre el deseo de plena fenomenalización de finitudes y la necesidad, para esa misma fenomenalización plena, del "trasfondo" infinito e infenomenizable de la Idea. Esa tensión introduce una contradicción insoslayable e "indepurable" en el seno del discurso fenomenológico, pero a su vez anuncia la "nueva lógica" de la différance.

\footnotetext{
${ }^{26}$ Esta hipotética producción "diferancial" auténtica puede considerarse también desde el punto de vista de un ser que se produjera más allá del ente, es decir, de forma no histórica. Sería un ser que no se distinguiría en nada de la nada. Derrida considera esta (im)posibilidad en "Violencia y metafísica", al hablar de la (im)posibilidad de un ser sin violencia: "Un ser sin violencia sería un ser que se produjera fuera del ente: nada; no-historia; no-producción; no-fenomenalidad. Una palabra que se produjera sin la menor violencia no determinaría nada, no diría nada, no ofrecería nada al otro; no sería historia y no mostraría nada; en todos los sentidos de esta palabra, y en primer lugar en su sentido griego, sería una palabra sin frase" (Derrida, 1989: 200). Así, una différance puramente interna al sentido, que lo produjera históricamente pero sin violentarlo, terminaría sin producir nada.
} 
| Artigos | Poder de reactivación y poder de différance: sobre la importancia de Husserl en la obra temprana de Derrida | Pedro Natán Tenner |

En el marco de esa contradicción, hemos resaltado un caso particular: cómo esta tensión entre finitud e infinitud se pone de manifiesto en una consideración sobre la finitud del poder. Mientras que, para garantizar la plena fenomenalización del sentido en determinaciones finitas, Husserl deberá postular un poder infinitizable, Derrida resaltará el carácter irreductible de la finitud del poder. Un poder que alcanzara la plenitud de la Idea o de la vida transcendental (es decir, una différance que fuera plenamente ella misma) no permitiría la constitución de un sentido pleno y transparente, sino que provocaría el fin irremediable del sentido. Para constituirse como tal, la transparencia del sentido deberá permitir una opacidad: la de la finitud irreductible de una différance que nunca dejará de amenazar con la muerte del mismo sentido que produce.

\section{Referências bibliográficas}

\section{Primaria}

Derrida, J. (1979), "Scribble, writing-power" [trad. Plotkin], en Yale French Studies, 58, pp. 117-147.

Derrida, J. (1985), La voz y el fenómeno [trad. Peñalver], Valencia, Pre-Textos.

Derrida, J. (1986), De la gramatología [trad. Del Barco y Ceretti], México DF, Siglo Veintiuno

Derrida, J. (1989), La escritura y la diferencia [trad. Peñalver], Barcelona, Anthropos.

Derrida, J. (1994), "La différance", en Derrida, J. (1994), Márgenes de la filosofía [trad. González Marín], Madrid, Cátedra.

Derrida, J. (1997), Mal de archivo [trad. Vidarte Fernández], Trotta.

Derrida, J. (2000), Introducción al origen de la geometría [trad. Cohen], Buenos Aires, Manantial.

Heidegger, M. (2000), Nietzsche [trad. Vermal], t. 2, Barcelona, Ediciones Destino.

Husserl, E. (1962), Ideas I [trad. Gaos], México DF, FCE.

Husserl, E. (2000), El origen de la geometría [trad. Waksman], Buenos Aires, Manantial. 
| Artigos | Poder de reactivación y poder de différance: sobre la importancia de Husserl en la obra temprana de Derrida | Pedro Natán Tenner |

\section{Secundaria}

Baring, E. (2011), The Young Derrida and French Philosophy, Cambridge, Cambridge University Press.

Bernet, R. (1993), "Derrida-Husserl-Freud: The Trace of Transference", en The Southern Journal of Philosophy, XXXII, suplemento, pp.141-158.

Bower, M. (2015), "Husserl's Concept of the Vorwelt and the Possible Annihilation of the World", en Research in Phenomenology, 45, pp. 108-126.

Ferraris, M. (2006) Introducción a Derrida. (Trad. L. Padilla López), Buenos Aires, Amorrortu.

Lawlor, L. (2002), Derrida and Husserl - The Basic Problem of Phenomenology, Indiana, Indiana University Press.

Moati, R. (2015), "Fenomenología y dialéctica. Derrida crítico de Tran Duc Thao", en Bórquez (comp.), Fenomenología, firma, traducción, Santiago de Chile, Pólvora.

Sorin, A. (2018), "Dialéctica y escritura. Notas para una lectura problemática de los primeros pasos derridianos (1954-1962)", Factótum, 20, pp. 20-31.

Staiti, A. (2014), Husserl's Transcendental Phenomenology - Nature, Spirit and Life, Cambridge, Cambridge University Press.

Vitale, F. (2018), Biodeconstruction [trad. Serratore], Albany, Suny Press.

Recebido em: 21/06/2020 | Aprovado em: 23/12/2020 